\section{Coming Events}

2016

2016 MRS Spring Meeting

March 28-April 1, 2016

Phoenix, AZ

www.mrs.org/spring2016

EPMA 2016: Electron Probe Microanalysis

Topical Conference

May 16-19, 2016

Madison, WI

www.microbeamanalysis.org/topicalconferences/

epma-2016-1/epma-2016

APMC11 - 11th Asia-Pacific Microscopy

Conference

May 23-27, 2016

Phuket, Thailand

www.apmc11.org

EBSD 2016 Electron Backscatter

Diffraction Topical Conference

May 24-26, 2016

Tuscaloosa, AL

www.microbeamanalysis.org/topical-conferences/

ebsd-2016/welcome

Inter/Micro: 68th Annual Applied

Microscopy Conference

June 6-10, 2016

Chicago, IL

www.mcri.org

43rd MSC Annual Meeting

June 7-10, 2016

Edmonton, Alberta

http://conference2016.msc-smc.org

Microscopy \& Microanalysis 2016

July 24-28, 2016

Columbus, $\mathrm{OH}$

www.microscopy.org

European Microscopy Congress

August 28-September 2, 2016

Lyon, France

http://emc2016.fr

\section{7}

Microscopy \& Microanalysis 2017

July 23-27, 2017

St. Louis, MO

www.microscopy.org

\section{8}

Microscopy \& Microanalysis 2018

August 5-9, 2018

Baltimore, MD

www.microscopy.org

\section{9}

Microscopy \& Microanalysis 2019

August 4-8, 2019

Portland, OR

www.microscopy.org

\section{0}

Microscopy \& Microanalysis 2020

August 2-6, 2020

Milwaukee, WI

www.microscopy.org

More Meetings and Courses

Check the complete calendar near the

back of this magazine.

\title{
How an Ant Cleans its Antennae
}

\author{
Stephen W. Carmichael \\ Mayo Clinic, Rochester, MN 55905 \\ carmichael.stephen@mayo.edu
}

Most insects, including ants, depend on sensory input from their antennae for survival: obtaining food, finding mating partners, and avoiding predators. Contamination of the surfaces of the antennae, both by abiotic contaminants (dust, salt, ash, etc.) and biologic contaminants (bacteria, spores, parasites, etc.), can interfere with the function of the sensory systems and therefore be life-threatening. Insects have developed a variety of mechanisms to cope with surface contamination. In addition to passive cleaning mechanisms such as equipping the body surface with super-hydrophobic material (as exhibited by the leaves of the lotus flower, known as the "lotus effect") insects actively groom their body surface with specialized cleaning structures on their legs. These cleaning activities take up to $30 \%$ of their lifetimes! Insect grooming movements have been classified as "rubbing" where cleaning is performed by an appendage sweeping back and forth, "scraping" with unidirectional movements performed by a cleaning structure, and "nibbling" where cleaning is performed by the insect's mouthparts. Recently, Alexander Hackmann, Henry Delacave, Adam Robinson, David Labonte, and Walter Federle used scanning electron microscopy (SEM) to study the functional morphology of the antenna cleaner in Camponotus rufifemur ants [1]. In addition they quantified the efficiency of the cleaner apparatus.

During an antenna cleaning movement, the ants lower their head, insert their antenna into a clamp-like cleaning structure on the front leg of the same side, and pull it through. After the actual grooming movement, the antenna cleaner is then cleaned by the ants' mouthparts (nibbling) in order to allow reuse. The cleaning structure in almost all ant species consists of a curvature on the front tarsus (called the tarsal notch) that faces a spur originating from the tibia. Each side of the clamp bears hair arrays that can be subdivided into "bristles," "combs," and "brushes" that are outgrowths of the cuticle (Figure 1).

Hackmann et al. simulated cleaning strokes by moving a notch and a spur over antennae contaminated with fluorescent particles of different sizes. The notch

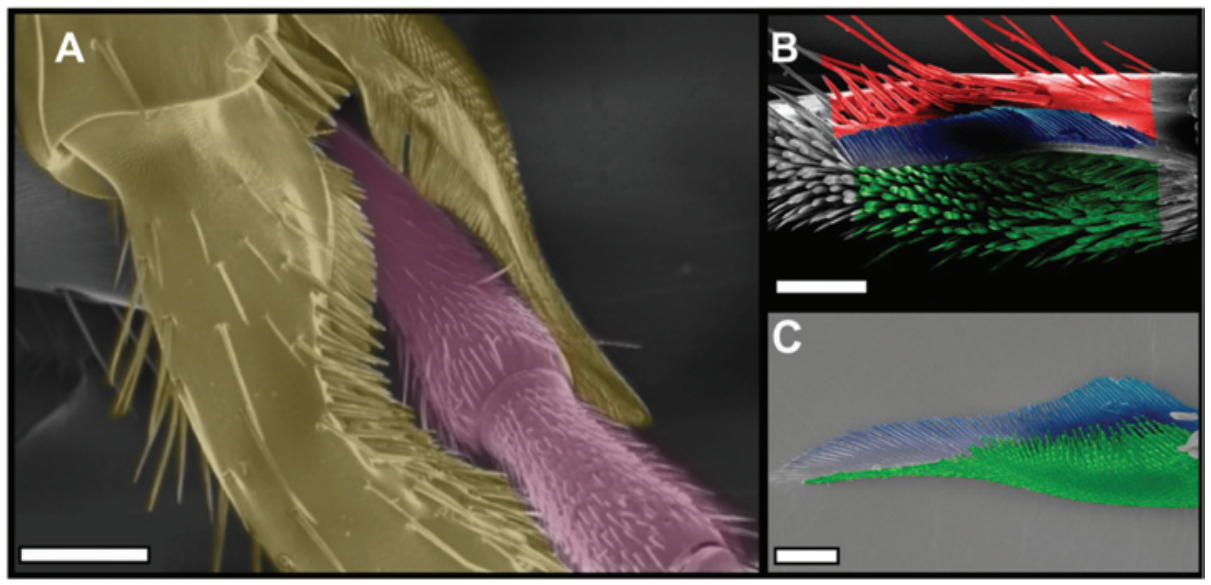

Figure 1: Antenna cleaner of $C$. rufifemur ants. (A) Scanning electron micrograph of the antenna clamped by the cleaner (viewed from the outer or posterior side). (B) Tarsal notch. (C) Tibial spur. Images in B and C are colored to show the bristles (red), the comb (blue), and the brush (green). Scale bars: (A) $150 \mu \mathrm{m}$, (B) $100 \mu \mathrm{m}$, (C) $50 \mu \mathrm{m}$. 
AVEN

Tailored To Fit

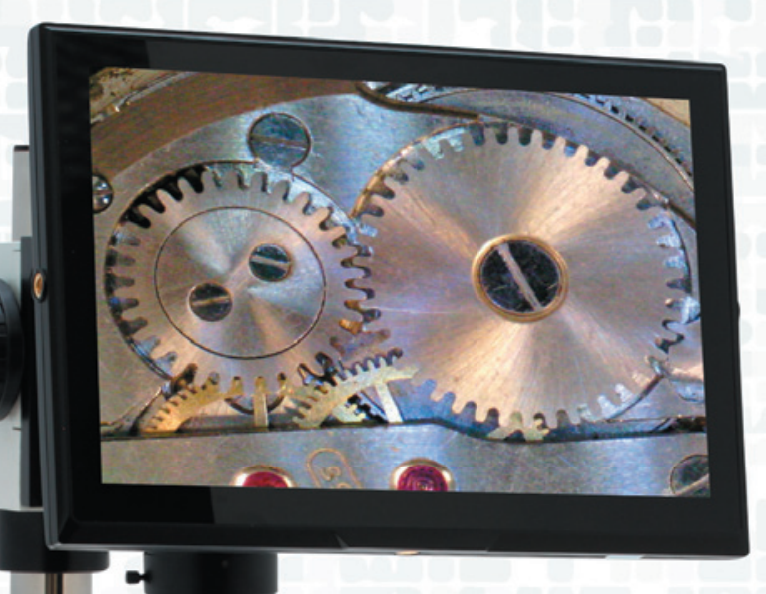

Item \# 26700-107-10

\section{Eliminate Eye Strain}

Prevent Neck Fatigue Enhance Productivity
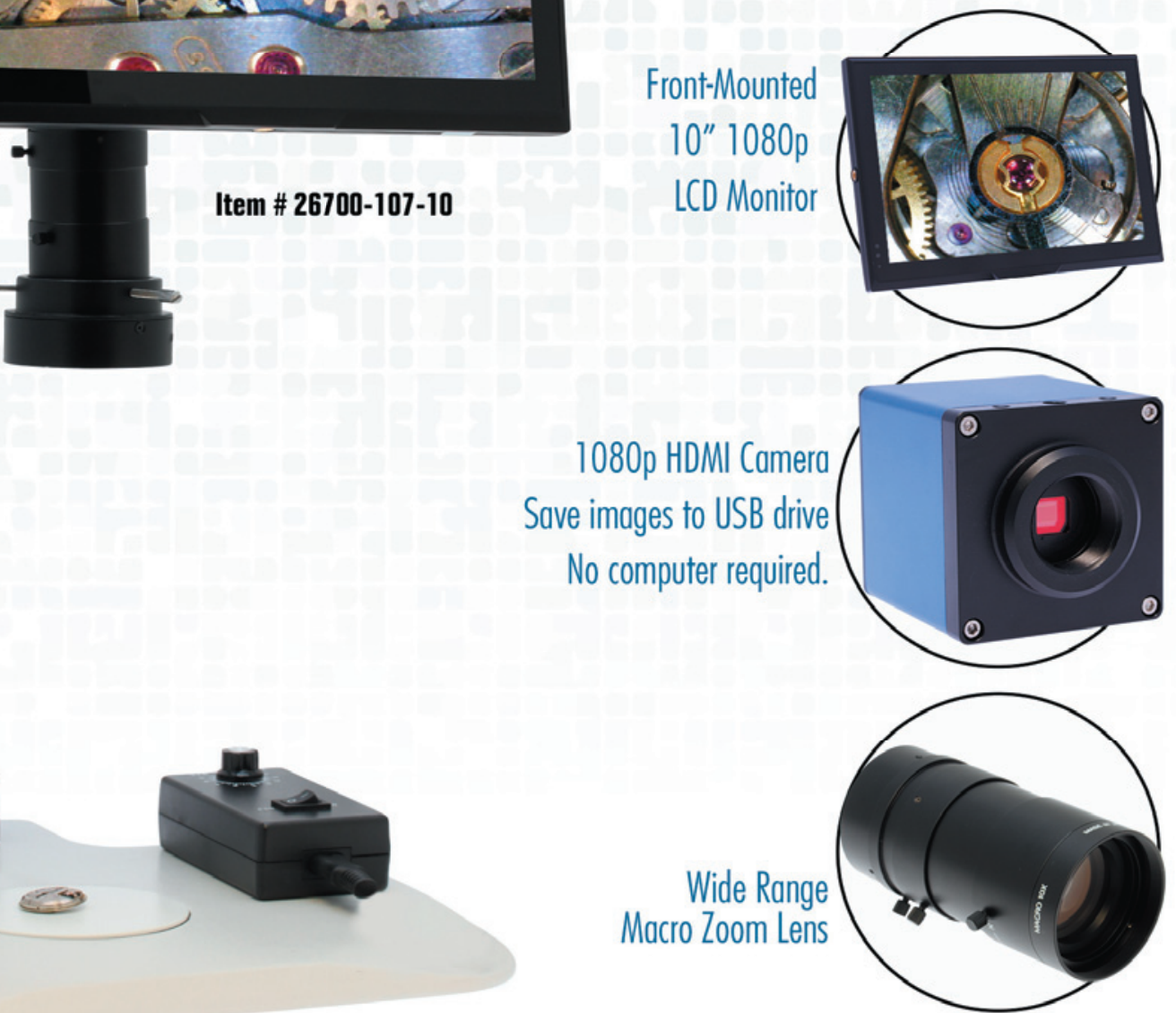

\section{Macro Vue HD Video Inspection System}

Eye strain is one of the most common challenges cited by frequent microscope users. Aside from being uncomfortable, it can negatively impact performance. That's why Aven has created the Macro Vue HD Video Inspection System.
This high magnification system allows operators to view images, save files, and share inspection on a monitor. By eliminating the fatigue associated with frequent microscope use, Macro Vue HD Systems are tailored for your productivity. Available with a standard stand or a dual arm boom stand. 
removed particles more efficiently than the spur, but both components removed more than $60 \%$ of the particles with the first stroke. Ablation of the bristles greatly reduced the cleaning efficiency, indicating they are essential for cleaning. Differentsized particles were trapped in distinct zones of the notch, proportional to the gap between the bristles. This suggests that the antenna cleaner operates as a sequential particle filter. The bristles pick up the largest particles from the antenna, and the comb removes particles that are smaller than the gaps between the bristles but larger than the gaps of the comb. In addition, there are flexible setae forming a brush that picks up even smaller particles. Whereas bristles and combs removed larger particles mechanically, the brush setae remove dirt particles by adhesion. The sequential particle filter mechanism prevents the very fine setae from being clogged by larger particles that have already been removed by the previous hair arrays. This is a fascinating mechanism that is essential for the survival of the ant, and its principles could inspire artificial cleaning devices for cleaning man-made surfaces on a micro- and even nano-scale.

\section{References}

[1] A Hackmann et al., Royal Society Open Science (2015) http://dx.doi.org/10.1098/rsos.150129.

[2] The author gratefully acknowledges Dr. Alexander Hackmann for reviewing this article.

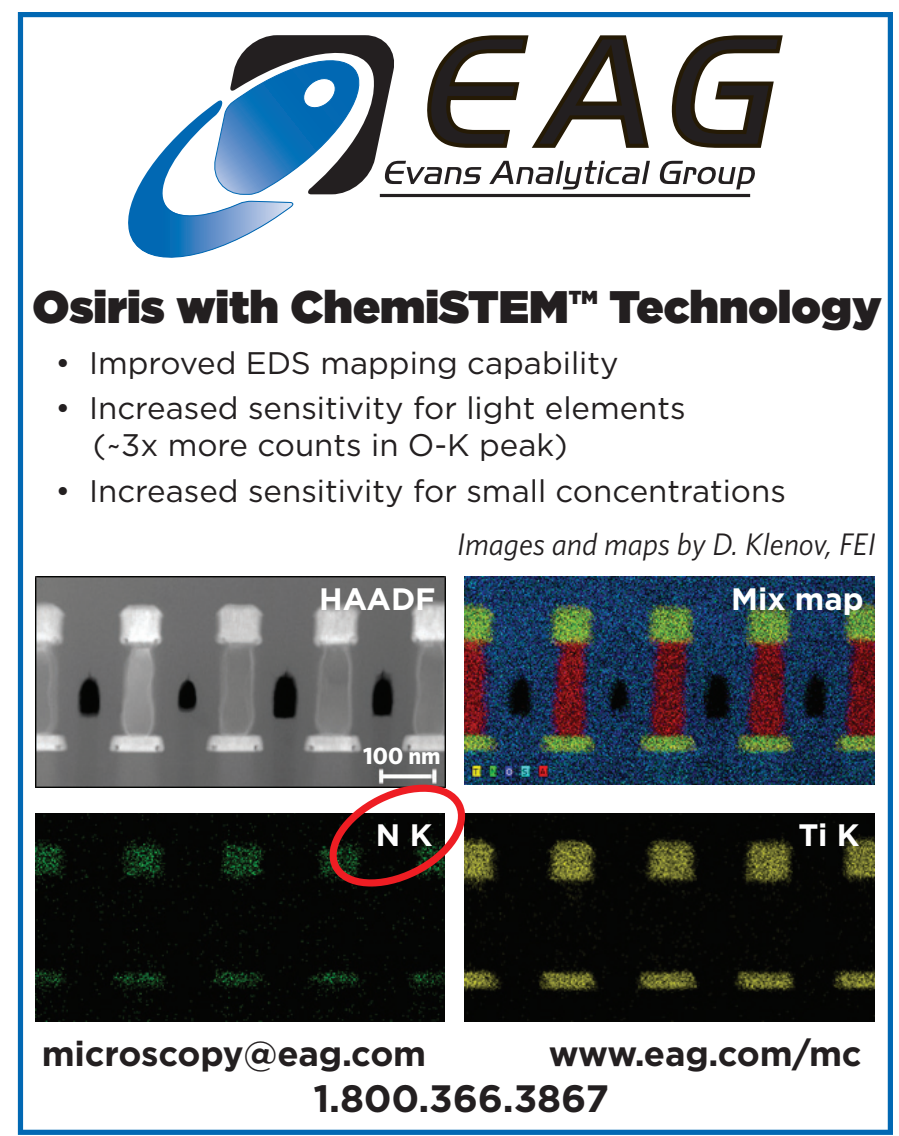

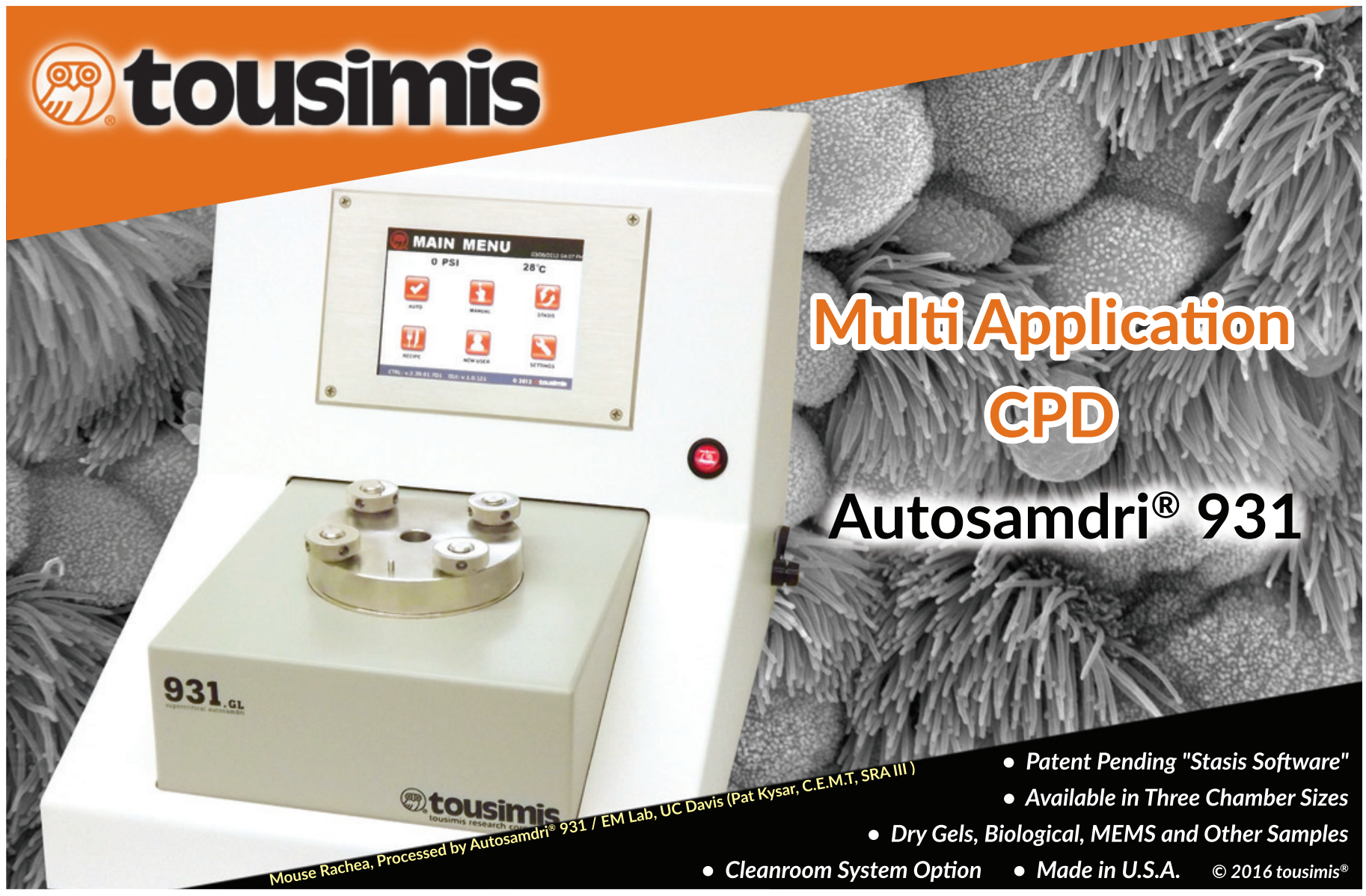




\section{The single source for all your microscopy supplies and specimen preparation equipment.}
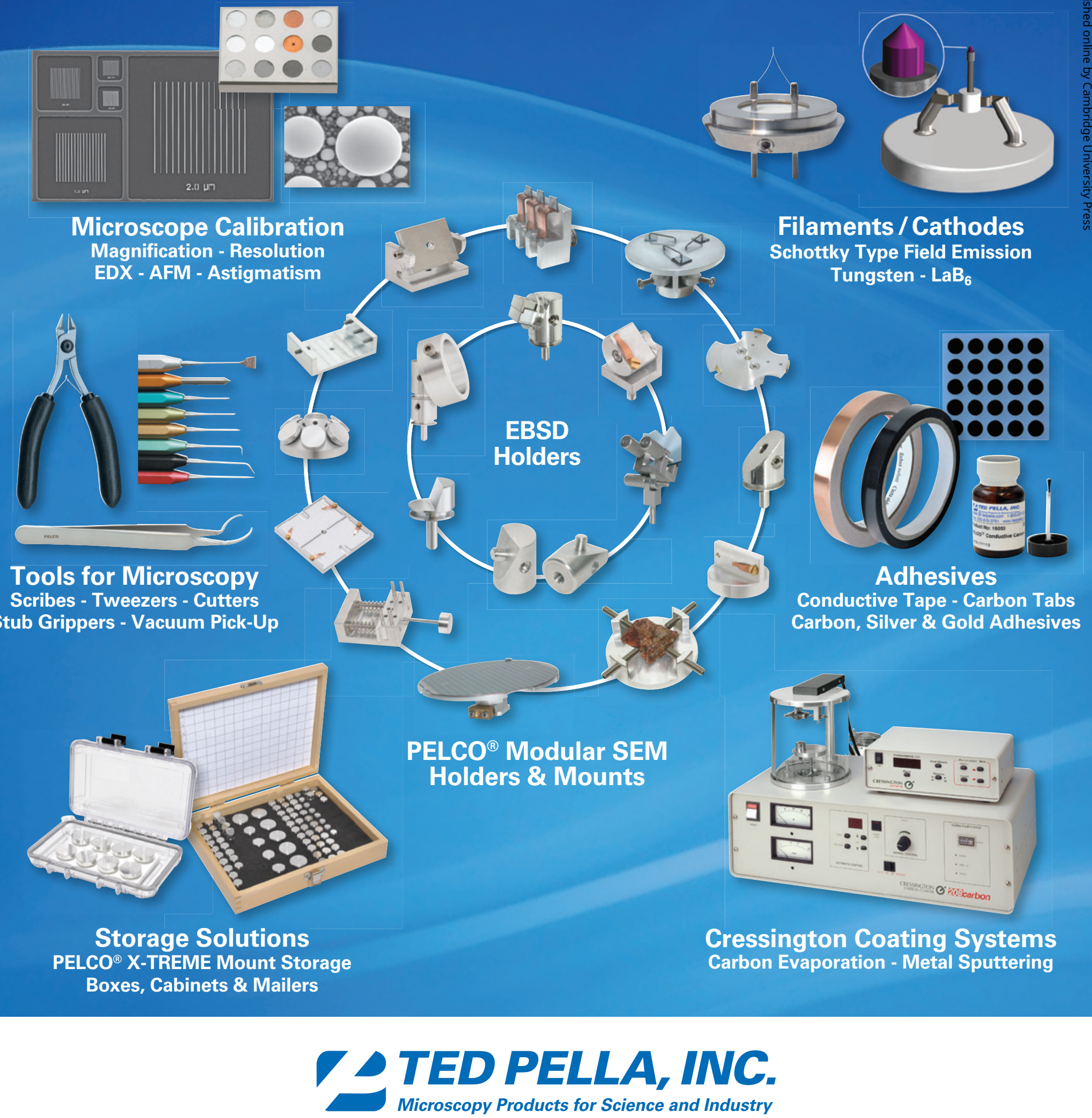

www.tedpella.com sales@tedpella.com 800.237.3526 